\title{
Menu Recommendation System Using Smart Plates for Well-balanced Diet Habits of Young Children
}

\author{
Kwon Namgung (D), Tae-Hwan Kim (D), and Youn-Sik Hong (iD \\ Department of Computer Science and Engineering, Incheon National University, Incheon 406-772, Republic of Korea \\ Correspondence should be addressed to Youn-Sik Hong; yshong@inu.ac.kr
}

Received 23 August 2019; Accepted 26 October 2019; Published 14 November 2019

Guest Editor: Shah Nazir

Copyright ( 2019 Kwon Namgung et al. This is an open access article distributed under the Creative Commons Attribution License, which permits unrestricted use, distribution, and reproduction in any medium, provided the original work is properly cited.

A well-balanced diet habit of a wide variety of foods and adequate nutrition can help to maintain proper growth and healthy life for young children. In Korea, young children aged 3 to 6 years use their own plates to eat lunch served in the kindergarten or childcare facilities. In this paper, we propose a smart plate that can easily measure how much food children have eaten. The smart plate has five load cell sensors to measure the weight of five places. Using them, the amount of food intake can be determined by measuring the weight of food before and after meals, respectively. This helps to know which foods young children prefer and which foods they do not prefer and identifies nutritional deficiencies in them. In addition, long-term accumulated data can be used to predict the growth index of young children. Finally, menus are recommended based on the nutrition facts consumed on a monthly basis by analyzing nutrition ingredients that were insufficient or excessive for children.

\section{Introduction}

Nutrients through diet are essential for body composition and healthy functioning of the body. In particular, the growth status of children is an important indicator of nutritional status because the exposed nutritional environment affects genetic growth potential. Since childhood is a time of formation of self, it is important to help them have right and healthy habits [1]. A well-balanced diet habit of a wide variety of foods and adequate nutrition can help to maintain proper growth and healthy life for infants [2]. The biggest problem of dietary status of young children is unbalanced, and the most common reason was unfamiliar taste [3].

Shim et al. [4] conducted the study to investigate the association between picky eating behaviors of preschool children and growth outcomes. They defined picky eating behaviors as the four constructs: eating a small amount (ES), neophobic behavior (NB), refusal of specific food groups (RF), and preference for specific food preparation methods (PP). Children with ES had lower height for age and weight for height than those without ES. In particular, picky eating of ES showed a risk of faltering height growth in preschool children.

Early childhood education institutions in Korea are divided into childcare facilities and kindergartens. Childcare facilities are targeted for preschoolers under 6 years of age (Childcare Act 2004). Kindergartens are aimed at children from 3 years of age to preschoolers (Early Childhood Education Act 2004). At present, most childcare facilities and kindergartens provide one or more meals and two or more snacks to the children. Since young children spend more than 35 hours per week in the aforementioned institutions, they will eat lunch and snacks at the same place. This means that their parents as well as the institutions make the children's weekday meals. For this reason, it is necessary to manage their meals at the institutions.

It is not easy to know how much food a young child ate every day. In this paper, we came up with the idea that young children aged 3 to 5 years carry their plates in their bags when they go to a kindergarten (or childcare facility). Young children eat lunch in kindergarten using their own plates. The children's standard plate is designed to hold food in five 
places, as shown in Figure 1. In other words, by using a smart plate that weighs, we not only know the food intake of a young child but also the nutritional intake. Based on this, it can provide food recommendation services that identify the nutritional deficiencies and correct their eating habits.

The smart plate has 5 load-cell sensors to measure the weight of 5 places. In addition, an RF identification tag is attached to identify individual food intake. Using the smart plates, the amount of food intake can be determined by measuring the weight of food before and after meals, respectively. This also helps to know which foods young children prefer and which foods they do not prefer and also identifies nutritional deficiencies in them. In addition, longterm accumulated data can be used to predict the growth index of young children.

Refer to the meal menu provided on a weekly basis as shown in Table 1 for information on the types of food and nutrients taken by young children at lunch. The nutrient content of the diet is based on the Korean nutrient standard dataset [5].

The smart plate-based food recommendation system has two functions to be implemented. First, we analyze the nutritional content that is insufficient or excessive based on the food intake taken by young children. In other words, based on the standard of intake of Korean nutrients based on the food intake, data such as calories, carbohydrates, protein, fat, and sodium are analyzed. Another function is to predict the growth index of young children. Notice that we assume that increase in height and weight of young children are proportional to the total metabolic rate of them. It predicts the expected growth index by comparing the actual growth rate of a young child in the last month and this month with the national standard growth rate. In addition, it predicts the increase in height and weight of a child using the estimated basal metabolic rate (BMR).

The remainder of this paper is organized as follows: Section 2 summaries related works. In Section 3, we explain the system configuration. Section 4 describes the food recommender system more in detail, and Section 5 presents experimental results. In Section 6, conclusions are given.

\section{Related Works}

Lee and Cho [6] investigated the eating behavior and food preference of preschool children in day care facilities. The parents reported that $34 \%$ of the children ate "Unbalanced diet." In addition, $16 \%$ of the children ate small portions of food. The parents picked up several reasons for their children's unbalanced diet, such as "Dislike of the tastes" (29.2\%), "Texture in the mouth" (28.6\%), and "Smell of food" (18.2\%). The unbalanced diet is to refuse unpleasant food as the self develops and is due to various reasons, including psychology, taste, and tactile reasons. They also pointed out that the preschooler's preference for vegetables is the lowest. It was found to be unfavorable because of the lack of experience with food.

The recent research [7] observed that dietary behavior of preschoolers was correlated with several factors, including dietary life-related knowledge, self-efficacy, and food

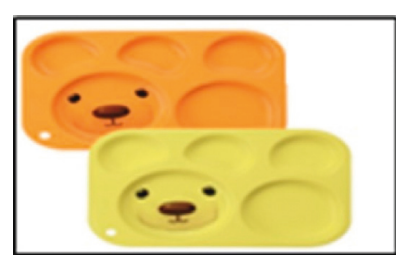

(a)

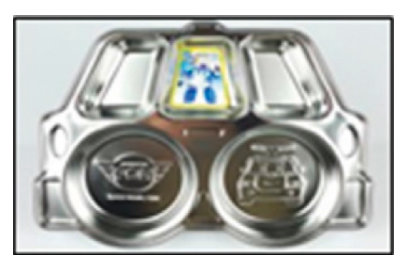

(b)
Figure 1: Children's plate.

preference. From the survey results [8], compared with girls, boys had more confidence in "Not overeating," and "Eating balanced meals with meat, fish, and vegetables." Thus, they suggested that it is necessary for nutrition education programs to consider the difference in food preference of preschoolers by gender.

Park et al. [9] studied about recommended dietary allowance (RDA) for young children and food guidelines for preschool children in Sweden. The aim of Swedish food guidelines was to increase energy, calcium, iron, and dietary fiber intake. From the Swedish RDA, the younger the person is, the lower the recommended amount of protein per $1,000 \mathrm{kcal}$ of energy, compared with the higher the recommended amount of fat. A high intake of carbohydrates lowers the rate of intake of fat, thus preventing obesity and preventing constipation and colorectal cancer. To maintain health and prevent cavities, young children are advised to consume less than $10 \%$ of their calories.

The most common approach in food recommender systems is collaborative filtering. The collaborative filtering [10] is a method of making predictions based on the user's interests by collecting preferences from many users. Content-based filtering [11] recommends items based on a comparison between the content of the items and a user's taste profile. Given the pros and cons of collaborative filtering and content-based recommenders, several studies tried a hybrid approach [12].

Like other systems, food recommenders suffer from data sparsity [14]. Not only may the total number of items be large but also items are usually nonstandardized. The authors [15] have clustered ingredients using $\mathrm{KNN}$ and $k$ means to create larger and denser neighborhoods.

Food recommender systems are related to healthier food choices. Elsweiler and Harvey [8] proposed meal plan recommendations for balanced nutrition. Their approach is to automatically create daily meal plans by first calculating the nutritional requirements of the user based on their personal characteristics. They aim to recommend food to people's preferred foods and nutrients in them so that they can go on a diet less painfully when recommending food for diet purposes. Elsweiler et al. [16] explored the feasibility of substituting meals that would typically be recommended to users with similar, healthier dishes.

Tran et al. [17] reviewed about two different approaches: recommendation techniques for individuals and recommendation techniques for groups. They also described popular recommendation approaches such as collaborative filtering recommendation, content-based recommendation, 
TABLE 1: Weekly lunch and snack menus for young children.

\begin{tabular}{|c|c|c|c|c|c|c|}
\hline Time & Monday & Tuesday & Wednesday & Thursday & Friday & Saturday \\
\hline $\begin{array}{l}\text { Morning } \\
\text { snack }\end{array}$ & Fruits & $\begin{array}{l}\text { Bean curd } \\
\text { porridge }\end{array}$ & Cucumber stick milk & Yogurt & Fruits & Soy milk \\
\hline Lunch & $\begin{array}{c}\text { Rice } \\
\text { Rib soup } \\
\text { Stewed pork } \\
\text { Seasoned aster } \\
\text { Kimchi }\end{array}$ & $\begin{array}{c}\text { Rice } \\
\text { Beef bone } \\
\text { soup } \\
\text { Tofu } \\
\text { Stir-fried } \\
\text { Vegetables } \\
\text { Kimchi }\end{array}$ & $\begin{array}{c}\text { Five-grain rice, Egg soup, Eggplant } \\
\text { stir-fry Kimchi }\end{array}$ & $\begin{array}{c}\text { Black-bean-sauce } \\
\text { on rice } \\
\text { Soy bean paste } \\
\text { soup } \\
\text { Hungarian pork- } \\
\text { chop } \\
\text { Acorn jelly } \\
\text { Kimchi }\end{array}$ & $\begin{array}{l}\text { Fried rice } \\
\text { Seaweed } \\
\text { soup } \\
\text { Beef } \\
\text { Cutlass fish } \\
\text { Stir-fried } \\
\text { octopus } \\
\text { Kimchi }\end{array}$ & \\
\hline $\begin{array}{l}\text { Afternoon } \\
\text { snack }\end{array}$ & $\begin{array}{c}\text { Mushroom pizza (or } \\
\text { omelet) } \\
\text { Milk }\end{array}$ & $\begin{array}{l}\text { Sweet potato } \\
\text { milk }\end{array}$ & Kimchi pancake & Noodle & $\begin{array}{l}\text { Rice cake } \\
\text { Plum tea }\end{array}$ & - \\
\hline $\mathrm{kcal} /$ Protein & $605 / 25$ & $543 / 24$ & $512 / 17$ & $606 / 20$ & $539 / 23$ & $302 / 12$ \\
\hline
\end{tabular}

and constraint-based recommendation. They pointed out that hybrid approaches are also employed in order to improve the recommender's performance.

An ideal AI recommender system [18] would be able to modify its recommendations based on the behavior, preferences, and needs of the user. However, since the AIbased recommender only applies to small-scale private datasets, there is a lack of confidence in calories or nutrition estimation results. Larger datasets such as Yummly-28K $(27,638)$ or Recipe $1 \mathrm{M}(887,706)$, which are built in the EU recently, could replace these smaller datasets.

\section{System Configuration}

The overall structure of the smart plate-based nutrition analysis system is shown in Figure 2. The smart plate has been designed with a structure that can hold five foods to model the actual plate. Thus, five load cells are attached underneath the smart plate.

The YZC-131A strain-gauge load cells are used. They convert the load acting on them into electrical signals. As the strain gauge is deformed, its electrical resistance changes in proportion to the load. It can measure up to $3 \mathrm{~kg}$ with $0.05 \%$ precision. As shown in Figure 2, we tested whether the load cell sensors accurately measured the weight. Based on the actual amount of food provided in kindergarten, the experiment was conducted on the weight of $10 \mathrm{~g}$ to $3 \mathrm{~kg}$, and the results are summarized in Table 2. Notice that the minimum weight measurement is $1 \mathrm{~g}$. There were no errors in the range of $20 \mathrm{~g}$ to $3 \mathrm{~kg}$. However, when measuring the weight of the object (screwdriver) of less than $10 \mathrm{~g}$ as shown in Figure 3(b), the relative error of up to $10 \%$ occurred when converting the analog value of the load cell sensor into the corresponding digital value. But, we tested a more heavier object which is $150 \mathrm{~g}$ as shown in Figure 3(a), and confirmed that the load cell sensor accurately measured its weight.

Two Arduino R3 modules were installed on the smart board. The Arduino R3 is equipped with the ATmega328 microcontroller. One Arduino module (called Weight Arduino) is responsible for managing the five load cells. Another Arduino board (called RFID Arduino) is responsible for recognizing RFID tags to identify who owns the plate. The Weight Arduino module is connected by USB to the Raspberry-pi 3 Model B for serial communication. The RFID Arduino uses ZigBee protocol for wireless communication to communicate with the Raspberry-pi board.

The RFID Arduino informs the Weight Arduino of the start time and the end time of lunch through RFID tag recognition. When the RFID Arduino informs the Weight Arduino of the start of measuring food weight, it is ready to measure the weight after zero adjustment. When the plate is ready to measure, place the food on the plate and measure its weight. After finishing the lunch, the RFID Arduino informs the Weight Arduino that the eating is over tag through RFID tag recognition. Then the Weight Arduino can measure the weight of the remaining food. This will allow us to know the amount of intake and the amount of leftovers. The weight values measured by the Weight Arduino are transferred to an integrated system via the Raspberry-pi board. These values are stored in the database implemented by MySQL. A single record stored in the database is shown in Table 3. It consists of the plate ID, the weight values of five places (represented as A, B, C, $\mathrm{D}$, and $\mathrm{E}$ ) before and after eating lunch, and date information.

\section{Food Recommender System}

It is assumed that a young child uses his (her) own smart plate, and according to weekly lunch menu, he(she) places each food in the proper location on the plate. The plate is weighed before and after each meal to calculate the amount of food taken by the child, and data is stored in the database. In order to calculate calories and nutrients obtained by a young child based on the food intake measured by the smart plate, data such as basic metabolism rate (BMR), nutrients contained in food, and RDA for young children are needed. Through this, it is possible to predict the growth index of a child or recommend the menu according to his (her) nutrition intake.

4.1. BMR (Basal Metabolism Rate). BMR is the minimum amount of energy needed per day to sustain life (the amount of energy used primarily by the brain, heart, and internal 


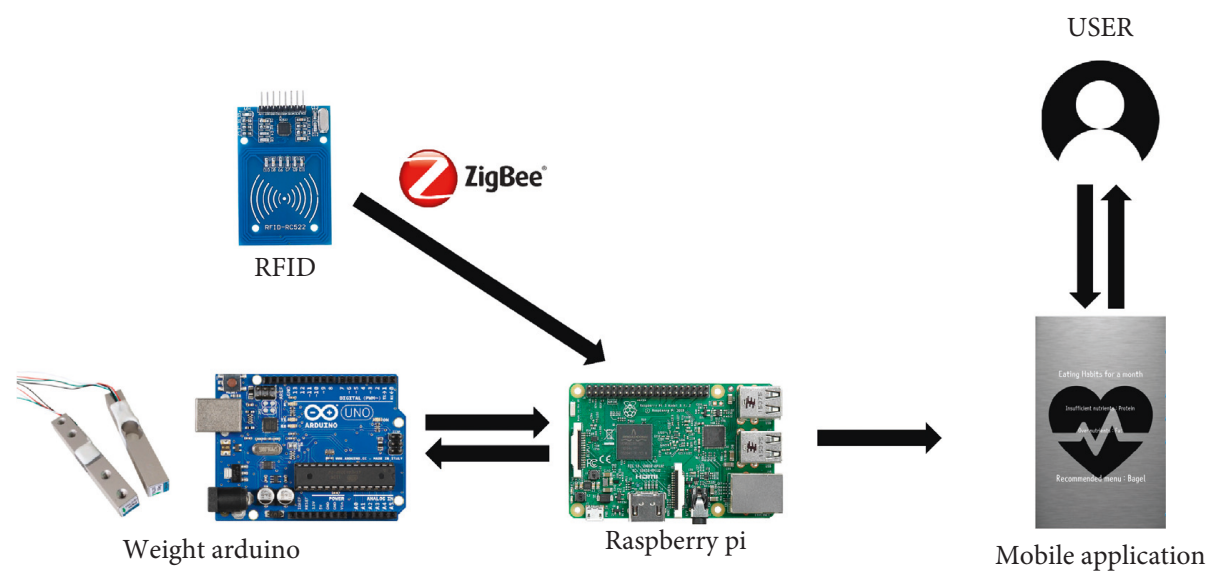

FIGURE 2: The overall process of smart plate-based nutrition analysis system.

TABLE 2: Weekly lunch and snack menus for young children.

\begin{tabular}{lccc}
\hline Trial & Actual weight $(\mathrm{g})$ & Measured weight $(\mathrm{g})$ & Relative error ratio (\%) \\
\hline 1 & 150 & 150 & 0 \\
2 & 100 & 100 & 0 \\
3 & 50 & 50 & 0 \\
4 & 25 & 25 & 0 \\
5 & 10 & 9 & 10 \\
\hline
\end{tabular}

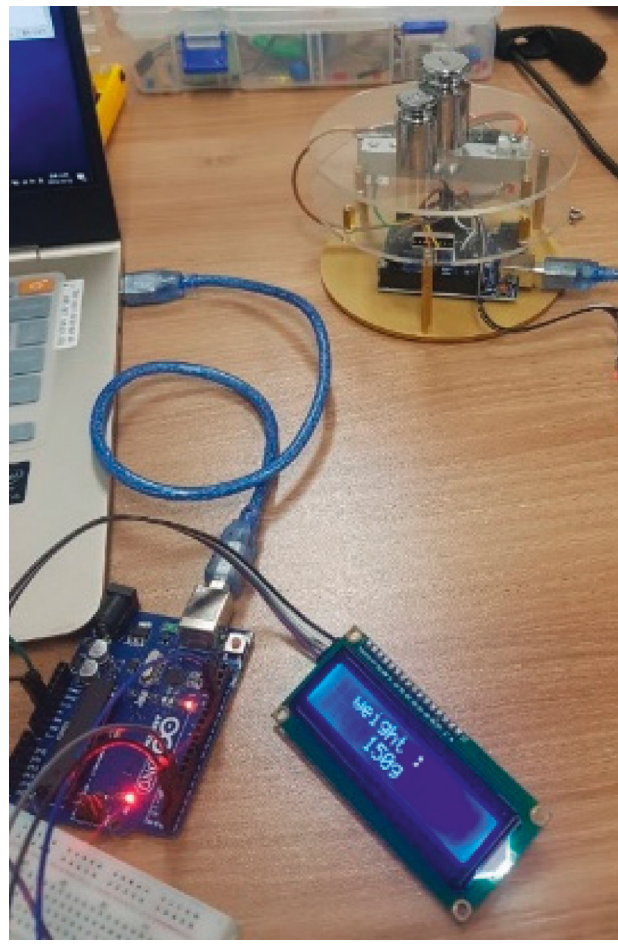

(a)

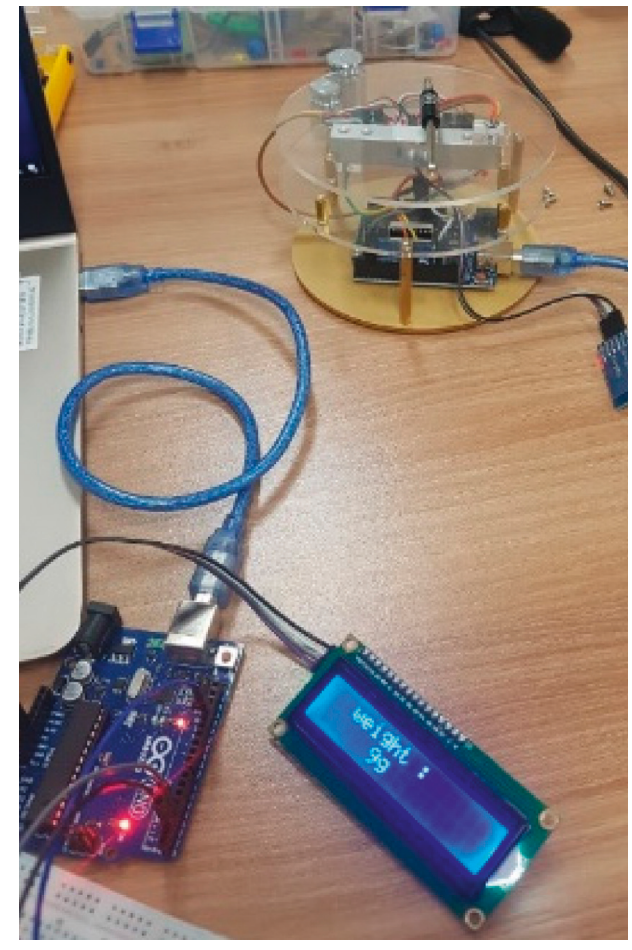

(b)

FIgURE 3: Experiments to check the weighing accuracy of the load cell sensor. (a) Test with the weight of $150 \mathrm{~g}$. (b) Test with the screwdriver weighing $10 \mathrm{~g}$. 
TABLE 3: The single record of the plate stored in the database.

\begin{tabular}{lccccc}
\hline The plate ID & Place A & Place B & Place C & Place D & Place E \\
\hline 154201202115 & Rice & Kimchi & Seasoned aster & Rib soup & Stewed pork \\
Amount of food served (g) & 123 & 30 & 23 & 18 & 40 \\
Amount of food served (g) & 25 & 10 & 5 & 80 & 20 \\
Amount of food intake (g) & 98 & 20 & & 69 \\
\hline
\end{tabular}

organs), affected by gender, age, and physique. Knowing a young child's age, height, and weight, we calculate nutritional requirements for a young child using a version of the Harris-Benedict equation [19].

$$
\begin{aligned}
\text { Boy }= & 66.473+(13.752 \times \text { weight }[\mathrm{kg}]) \\
& +(5.003 \times \text { height }[\mathrm{cm}])-(6.755 \times \text { age }[\text { year }]) \\
\text { Girl }= & 655.096+(9.563 \times \text { weight }[\mathrm{kg}]) \\
& +(1.85 \times \text { height }[\mathrm{cm}])-(4.676 \times \text { age }[\text { year }])
\end{aligned}
$$

The aforementioned equation has been revised by Roza [13], which estimates an individual's BMR and daily calorie requirements. Elsweiler and Harvey [8] suggested that the estimated BMR value is multiplied by a number between 1.2 and 1.9 corresponding to the individual's activity level giving a recommended daily energy intake to maintain the current body weight. In this paper, various factors such as energy consumption due to exercise or energy increase due to drinks and between-meal snacks are not considered.

4.2. Food Classification and Nutritional Facts by Food. The calories and nutritional content of the foods taken by young children in childcare facilities can be obtained by the dataset provided by the National Food Safety Information Service [5]. As shown in Table 4, foods were classified into five groups, such as rice, Kimchi, vegetable, soup, and meat/ fish. On the other hand, it is possible to obtain the expected nutritional intake based on the amount of food provided for each menu included in the weekly menu (Table 1). Table 4 shows the expected nutrition (carbohydrate, fat, sugar, and sodium) based on the food content of the five places on the smart plate.

The standard dataset for height and weight of boys and girls has been built by referring to the Development of the 2017 Korean National Growth Charts for children and adolescents [20, 21]. In addition, the 2015 dietary reference intakes for Koreans [22] has been used to utilize the minimum nutrition necessary for growing children. The recommended protein intake and proportion of fat energy intake by age are shown in Table 5 . Notice that fat is an important nutrient that functions as an energy source and regulates metabolites.

4.3. The Process of Food Recommendation. Based on the calories $f_{i}(\mathrm{kcal} / \mathrm{g})$ of $i$-th food and the amount amount ${ }_{i}(\mathrm{~g})$ eaten by a child, the total calorie $\mathrm{Cal}_{\text {total }}$ from food intake can be obtained as follows:

$$
\mathrm{Cal}_{\text {total }}=\sum_{i=1}^{N} f_{i} \times \text { amount }_{i} \text {, }
$$

where $N$ is the number of food location in the smart plate, i.e., 5. As shown in Table 4, various nutrient intakes can be obtained based on the food taken by a child. This will identify the nutrients he (she) lacks. We calculate the cumulative nutrients he (she) has taken for a month and then compare it with the recommended and sufficient nutrition intakes. However, the only thing that can be measured with a smart plate is a lunch at the childcare facilities. The types and amount of food eaten at home were collected through a survey. Through this, we predict the daily intake of nutrients and the monthly intake of nutrients.

Finally, we recommend a group of foods that can supplement a young child's nutrient deficiencies. If he (she) frequently eats foods that exceed the threshold of nutrient intakes, these foods are not recommended. For example, if one lacks protein intake, the recommendation menu includes the foods that are easy to take with high protein. If the proportion of fat-energy intake during one month is within 15 to $30 \%$ of the calories, it is decided to be normal. If it exceeds 30\%, low-fat foods are recommended. However, if it is less than 15\%, high-fat foods are recommended.

4.4. Prediction of Growth in a Month. The dataset about agespecific standard BMR, height, and weight can be obtained from Development of the 2017 Korean National Growth Charts for children and adolescents [20]. Compared with these standard growth indicators, the growth index of the child under analysis can be predicted. Assuming that the child continues to grow at the current pace, one's BMR changes over the past two months (last month and this month) can be used to predict the BMR for the next month.

Let $\mathrm{BMR}_{m}^{\text {target }}$ andBMR ${ }_{m}^{\text {std }}$ be the BMR of the child under analysis and the standard BMR, respectively. Notice that $m$ and $m-1$ indicate this month and last month, respectively. The expected growth index of a child can be calculated as shown in the following equation:

$$
\text { growth index }=\frac{\mathrm{BMR}_{m}^{\mathrm{target}}-\mathrm{BMR}_{m-1}^{\mathrm{target}}}{\mathrm{BMR}_{m}^{\mathrm{std}}-\mathrm{BMR}_{m-1}^{\mathrm{std}}} .
$$

Assuming that the BMR for the next month of the child under analysis is the same as this month, the $\mathrm{BMR}_{m+1}^{\text {expected }}$ for the next month of this child can be estimated as shown in the following equation: 
TABLE 4: Food classifications and nutrition facts of food [5].

\begin{tabular}{|c|c|c|c|c|c|}
\hline & & Menu id & Menu group & Menu name & Weight (g) \\
\hline \multicolumn{6}{|l|}{ Location on the plate } \\
\hline A & & 39 & Rice & Rice & 200 \\
\hline $\mathrm{B}$ & & 607 & Kimchi & Kimchi & 50 \\
\hline $\mathrm{C}$ & & 544 & Vegetable & Seasoned aster & 50 \\
\hline $\mathrm{D}$ & & 229 & Soup & Rib soup & 600 \\
\hline $\mathrm{E}$ & & 490 & Fish/meat & Stewed pork & 70 \\
\hline Location on the plate & $\mathrm{kcal}$ & $\mathrm{kcal} / \mathrm{g}$ & Carbohydrate (g) & Protein $(\mathrm{g})$ & Fat $(g)$ \\
\hline $\mathrm{A}$ & 272 & 1.36 & 66.4 & 6 & $0.2^{\circ}$ \\
\hline $\mathrm{B}$ & 19.13 & 0.38 & 2.9 & 1.23 & 0.29 \\
\hline $\mathrm{C}$ & 74 & 1.48 & 3.3 & 1.35 & 6.15 \\
\hline $\mathrm{D}$ & 236.75 & 0.39 & 7.61 & 27.38 & 10.76 \\
\hline $\mathrm{E}$ & 115.71 & 1.65 & 4.98 & 8.55 & 6.86 \\
\hline Location on the plate & Sugar (g) & Sodium (mg) & Cholesterol (mg) & Saturated fatty acid (g) & Trans fatty acid (g) \\
\hline $\mathrm{A}$ & 0 & 6 & 0 & 0 & 0 \\
\hline $\mathrm{B}$ & 0.79 & 312.08 & 1.13 & 0.06 & 0 \\
\hline $\mathrm{C}$ & 0 & 281.86 & 0 & 0.85 & 0.05 \\
\hline $\mathrm{D}$ & 0 & 1717.54 & 112.25 & 2.86 & 0.16 \\
\hline $\mathrm{E}$ & 0 & 279.57 & 0 & 0 & 0 \\
\hline
\end{tabular}

TABLE 5: Recommended protein intake and proportion of fat energy intake by age.

\begin{tabular}{lcc}
\hline Age & Recommended protein intake (g/day) & Proportion of fat-energy intake (\%) \\
\hline 3 & 20 & $15-30 \%$ of total calories \\
4 & 30 & \\
5 & & \\
\hline
\end{tabular}

$$
\begin{aligned}
\mathrm{BMR}_{m+1}^{\text {expected }}= & \mathrm{BMR}_{m}^{\text {target }}+\left(\mathrm{BMR}_{m+1}^{\text {std }}-\mathrm{BMR}_{m}^{\text {std }}\right) \times \text { growth } \\
& - \text { index. }
\end{aligned}
$$

4.5. Menu Recommendation. We categorize the menu dataset based on insufficient or overfed nutrients obtained in the previous section. The recommended food dataset uses the database provided by the National Food Safety Information Service [5]. Most countries, including Sweden [9], specify RDAs of carbohydrate, protein, and fat for young children in their nutrition recommendation. In Korea, carbohydrates are staple foods, so management of fat and protein intake for young children is a major concern $[4,6,7,20,21]$. Especially, menus related to protein and fat are interrelated, so clustering is possible. Therefore, menu classification is performed based on these nutrients. We do cluster various foods into four groups based on protein and fat ingredients by applying $k$-means clustering algorithm. We try to find the homogeneous subgroups within the data such that data points in each cluster are as similar as possible according to a similarity measure such as protein and fat ingredients.

4.5.1. Outlier Removal. To achieve an effective clustering result, data preprocessing is required. Outliers are values that are significantly outside a typical data range. Clustering does not work well if there is an outlier in the dataset. After deploying the dataset on a two-dimensional plane, it is divided into four areas $(Q 1, Q 2, Q 3$, and $Q 4)$, as shown in Figure 4. Initially, the horizontal areas $((Q 1, Q 2)$ and $(Q 3$, $Q 4))$ and the vertical areas $((Q 1, Q 3)$ and $(Q 2, Q 4))$ are set to be the largest to cover all the datasets. Let's assume that the threshold is $90 \%$ and this value is adjustable. First, the size of the two horizontal areas are reduced by $\alpha(0<\alpha<0.1)$, so that more than $90 \%$ of the dataset is included in these areas. Then, the size of the two vertical areas are reduced by $\beta(0<\beta<0.1)$. Repeat this process until the dataset is maintained at at least $90 \%$. This can effectively eliminate the outlier.

Figure 5 shows the results of $k$-means clustering without removal of outliers. Of the 1000 data, we removed 96 outliers to improve the results of $k$-means clustering. Of these, 34 menus related to protein ingredients and 60 menus related to fat ingredients.

4.5.2. Clustering Menus for Recommendation. The menu dataset after preprocessing is categorized into four clusters based on protein and fat facts: low protein low fat, high protein low fat, low protein high fat, and high protein high fat. Table 6 shows the nutritional information for protein and fat for the typical menus used in the classification process. The clustered results are shown in Figure 6 using four colors (red, orange, blue, and green). Notice that the star symbol in Figure 6 represents the center of each cluster. If our proposed system is to be determined as a high-protein low-fat menu, it should recommend one among those belonging to the orange cluster. Among the menus in the same cluster, the selection range can be limited according to insufficient 


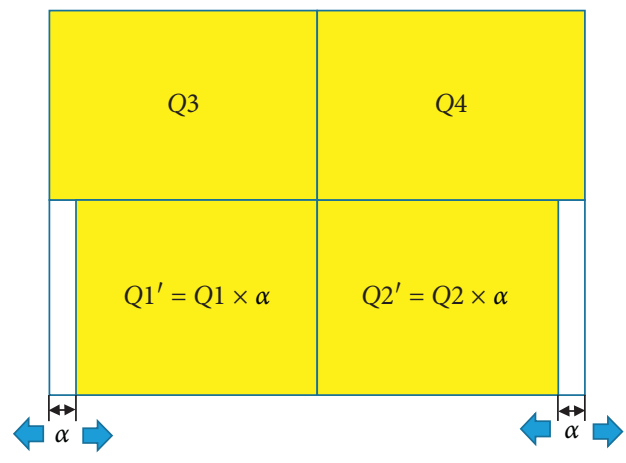

(a)

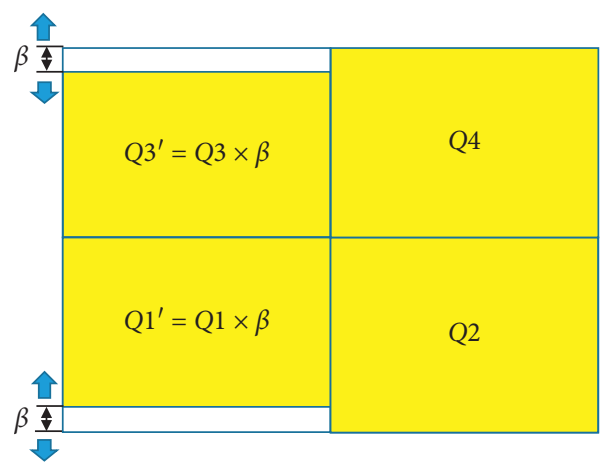

(b)

Figure 4: Adjustment of the horizontal area and vertical area for outlier removal.

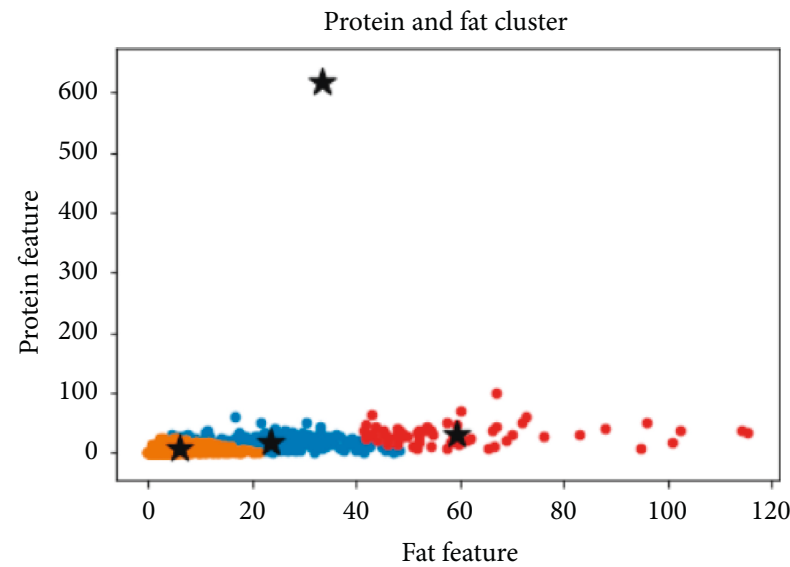

FIgURE 5: The results of $k$-means clustering without outlier removal.

nutrition. Table 7 summarizes typical menus belonging to each cluster.

\section{Experimental Results}

The data were obtained from Haedoongsil day care center on our campus. The center provides us weekly meal and snack menu as shown in Table 1. However, it was not possible to have children directly use the smart plates for many reasons, including hygiene issues. For collecting dataset, the weight of each menu was measured immediately after they received the food, and once again, after the meal, the weight was measured to get the food intake of the children. As we pointed out earlier, the only thing that can be measured with the smart plate is a lunch at the childcare facilities.

For 10 young children, the amount of food they ate during lunch time in the kindergarten was actually measured with the smart plate. The smart plate has been made only for experimental purposes, so it is impossible to build this system directly in the house where a young child lives. Thus, types and amount of food eaten at home were collected through a survey. However, children's physical information such as height and weight is obtained from two actual measurements at every month under permission of their parents.
TABle 6: The nutritional information about protein and fat for clustering.

\begin{tabular}{lcc}
\hline Menu & Protein $(\mathrm{g})$ & Fat $(\mathrm{g})$ \\
\hline Fried kimchi rice & 23.07 & 20.27 \\
Fried rice & 18.79 & 27.5 \\
Shrimp sushi & 16.81 & 0.75 \\
Muffin & 7.37 & 28.23 \\
Mini tart & 3.14 & 23.59 \\
Bread with vegetable & 4.2 & 1.82 \\
Cheese cake & 7.22 & 20.63 \\
Rice cake stew & 20.63 & 4.46 \\
Rice noodle & 15.6 & 4.18 \\
Vegetable stew with potato & 3.32 & 2.46 \\
Red bean porridge & 18.43 & 3.68 \\
Seaweed soup & 3.03 & 0.72 \\
Sausage stew & 25.96 & 25.2 \\
White kimchi & 0.53 & 0.26 \\
Spicy marinated crab & 23.92 & 1.75 \\
Rice cake (bar shape) & 3.81 & 0.33 \\
Bulgogi burger & 20.88 & 26.72 \\
Garlic pizza & 23.86 & 26.36 \\
Glazed donut & 7.13 & 25.93 \\
Chicken croquette & 7.1 & 22.38 \\
\hline
\end{tabular}

5.1. Food Recommender Based on Nutrition Analysis. Table 8 shows the average nutrient intake per day for one of the children surveyed. It is the captured image of the content stored in the database. Notice that the two fields, overN and lackN represent nutrition fact exceeding the RDA and nutrition fact below the RDA, respectively. The value of this field is an index representing the nutrients (0: none, 1: carbohydrates, 2: protein, 3: fat; and 4: sodium).

According to the nutritional analysis in Table 8 , the child has been consuming too much fat and lacking protein, so it is necessary to recommend a high-protein low-fat food. Figure $7(\mathrm{a})$ is the part of the menus with the nutrition facts. In Figure $7(\mathrm{a})$, protein and fat are represented as one field (PF) because they are classified into the four clusters. The other two fields $\mathrm{C}$ and $\mathrm{N}$ represent carbohydrate and sodium, respectively. The value of the PF field corresponds to the index in Table 7. When the PF has 1, it indicates a low protein low-fat menu. The value of the field $\mathrm{C}$ is 1 for low carbohydrates and 2 for high carbohydrates. Similarly, the value of the field $\mathrm{N}$ is 1 for low sodium and 2 for high sodium. 


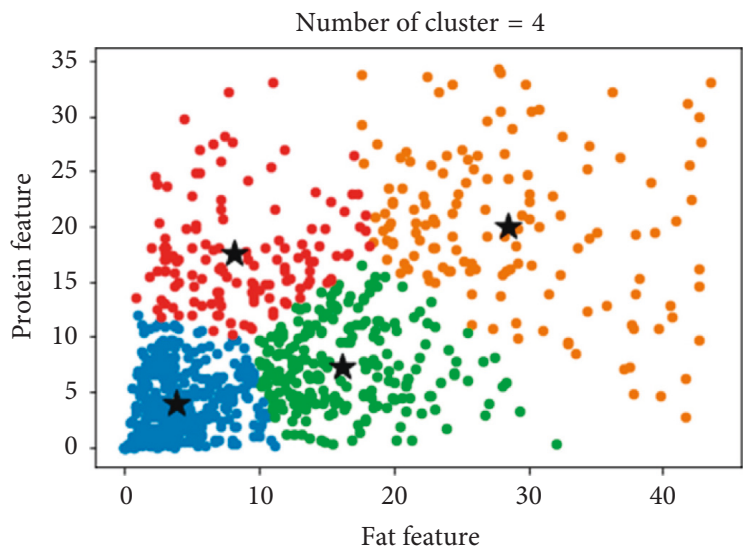

Figure 6: Classification of foods according to protein and fat.

TABLe 7: Typical menus belonging to each cluster.

\begin{tabular}{lcc}
\hline Index & Cluster & Typical menus belonging to the cluster \\
\hline 1 & Low protein low fat & Stir-fried octopus noodles, boiled dumplings, rice \\
2 & Low protein high fat & noodles \\
3 & High protein low fat & Fried shrimp roll, garlic bread, mushroom risotto \\
4 & High protein high fat & Mini burger, bagel, steamed kimchi dumplings \\
\hline
\end{tabular}

Table 8: The daily basis nutrition fact of the child under analysis.

\begin{tabular}{lcccccccc}
\hline Plate & Age & kcal & Carbohydrate & Protein & Fat & Na & OverN & LackN \\
\hline 30176100163 & 5 & 1440 & 271 & 15 & 56 & 1.78 & 3 & 2 \\
\hline
\end{tabular}

\begin{tabular}{lcccc}
\hline ID & Name & PF & C & N \\
\hline 1 & Octopus fried noodles & 1 & 1 & 1 \\
2 & Shrimp tempura roll & 2 & 2 & 2 \\
3 & Garlic bread & 2 & 1 & 1 \\
4 & Mini burger & 3 & 1 & 1 \\
5 & Bagel & 3 & 2 & 1 \\
6 & Kimchi fried rice & 4 & 2 & 2 \\
7 & Noodles with black soybean sauce & 4 & 2 & 2 \\
8 & Fried dumplings & 4 & 2 & 1 \\
9 & Kimchi dumplings & 3 & 2 & 1 \\
10 & Rice noodles & 1 & 1 & 1 \\
11 & Mushroom risotto & 2 & 2 & 1 \\
12 & Boiled dumplings & 1 & 1 & 1 \\
13 & Tofu vegetable fried rice & 3 & 2 & 1 \\
14 & Shrimp cup rice with lemon & 3 & 1 & 1 \\
15 & Rice with stir-fried seafood & 4 & 2 & 2 \\
16 & Sea squirt bibimbap & 3 & 2 & 1 \\
\hline
\end{tabular}

(a)

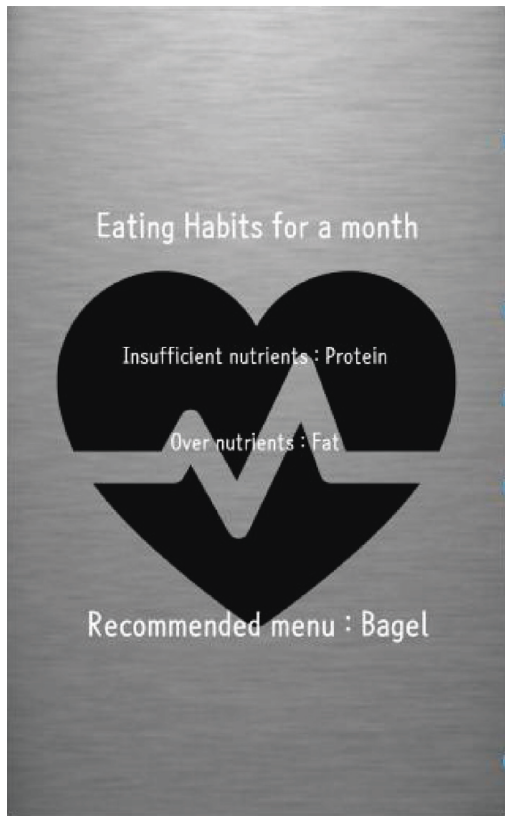

(b)

Figure 7: (a) The list of menu and (b) the recommended menu displayed in the smart phone. 
TABLE 9: Nutritional intake and physical development of a child subject to the case study.

\begin{tabular}{lc}
\hline Category & Child \\
\hline Gender & Female \\
Age & 56 months $(4$ years and $8 \mathrm{months})$ \\
Height/weight (2 months ago) & $98 \mathrm{~cm} / 14.3 \mathrm{~kg}$ \\
Height/weight (1 month ago) & $98 \mathrm{~cm} / 14.6 \mathrm{~kg}$ \\
Height/weight (present) & $99 \mathrm{~cm} / 15.0 \mathrm{~kg}$ \\
Estimated calories/protein/fat (during 1 month) & $1400 \mathrm{kcal} / 18 \mathrm{~g} / 47 \mathrm{~g}(\mathrm{about} 423 \mathrm{kcal})$ \\
\hline
\end{tabular}

TABLE 10: Comparison of standard BMR with the BMR for a child under investigation.

\begin{tabular}{lcc}
\hline Age (months) & Expected BMR & Standard BMR \\
\hline 54 & 954 & 961 \\
55 & 957 & 962 \\
56 & 962 & 965 \\
\hline
\end{tabular}

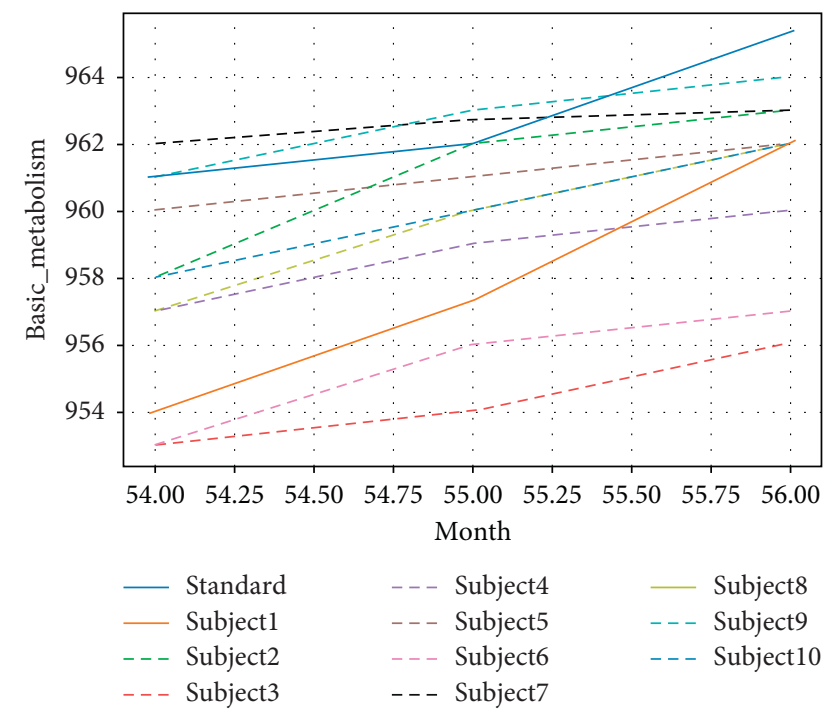

Figure 8: The expected BMR for the child under investigation.

Our proposed food recommendation system first recommends a menu that was frequently eaten by the child among high-protein, low-fat menus. The finally selected menu in this case is "Bagel." The system proposed in this paper has been linked with the mobile application, and the result of menu recommendation can be found on the smart phone as shown in Figure 7(b).

5.2. Expectation of Growth Index. The result of nutritional intake and two-month-long physical analysis for one of the children surveyed is summarized in Table 9. Based on this, the comparison of the expected BMR and the standard BMR over two months is shown in Table 10 . The child currently being analyzed has taken $1400 \mathrm{kcal}$ in the past month, indicating that she satisfied the RDA of calories. The protein intake is $18 \mathrm{~g}$, which does not meet the RDA of protein, so it is necessary to eat high-protein foods. Since the fat intake slightly exceeds the RDA (420 kcal) of total calories, it will be better to eat low-fat foods.

Using the aforementioned data, the child's weight and height were expected to be $14.99 \mathrm{~kg}$ and $100.65 \mathrm{~cm}$, respectively. Compared with the weight and height of the actual test subjects, the error rate was $0.001 \%$ for weight and $1.6 \%$ for height, respectively. The estimated BMR results for 10 people, the standard BMR, and 10 expected BMR changes are shown in Figure 8 Notice that subject1 in Figure 8 represents the BMR changes for the girl listed in Table 10.

\section{Conclusions}

We implemented the prototype of a smart plate that can easily measure how much food children have eaten. It has 5 load cell sensors to measure the weight of 5 places. There were no measurement errors in the range of $20 \mathrm{~g}$ to $3 \mathrm{~kg}$. However, the relative error of up to $10 \%$ occurred when measuring the weight of an object less than $10 \mathrm{~g}$ due to the error in analog to digital conversion.

The smart plate was used to obtain information about what food and how much a child ate. Based on this, it was determined how much nutrition intake the child needed, and growth rate was predicted by analyzing nutrients taken during a month. A total of 10 children were able to use their smart plate to get the amount of food they ate at lunch for a month. The smart plate has been made only for experimental purposes, so it is impossible to build this system directly in the house where a young child lives. Thus, types and amount of food eaten at home were collected through a survey.

We have established a dataset that links various food menus and nutritional information provided by authorized agencies. In particular, menus related to protein and fat are highly interrelated, so they were divided into the four clusters by applying $k$-means clustering algorithm. The menu was recommended based on the nutrition facts consumed for a month by analyzing nutrition ingredients that were insufficient or excessive for children. Under the same conditions, foods that children usually eat are included in the recommended menu. The response from children and parents to the menu recommendation was confirmed through a survey, and the positive response was much higher.

\section{Data Availability}

The JSON or CSV data except the personal information used to support the findings of this study are available from the corresponding author upon request.

\section{Conflicts of Interest}

The author declares that there are no conflicts of interest regarding the publication of this paper. 


\section{Acknowledgments}

This work was supported by the 2016 Grant of Incheon National University (grant no. 2016-2231).

\section{References}

[1] S. L. Anzman, B. Y. Rollins, and L. L. Birch, "Parental influence on children's early eating environments and obesity risk: implications for prevention," International Journal of Obesity, vol. 34, no. 7, pp. 1116-1124, 2010.

[2] E.-k. Kim, B. Song, and S.-Y. Ju, "Dietary status of young children in Korea based on the data of 2013 2015 Korea national health and nutrition examination survey," Journal of Nutrition and Health, vol. 51, no. 4, p. 330, 2018.

[3] Y. J. Oh and Y. K. Chang, "Children's unbalanced diet and parent's attitudes," Korean Journal of Nutrition, vol. 39, no. 2, pp. 184-191, 2006.

[4] J. E. Shim, J. H. Yoon, K. Kim, and H. Y. Paik, "Association between picky eating behaviors and growth in preschool children," Journal of Nutrition Health, vol. 46, no. 5, pp. 418-426, 2013.

[5] National Food Safety Information Service, Food and Nutrition Ingredients, National Food Safety Information Service, Seoul, South Korea, 2018, http://www.foodsafetykorea.go.kr.

[6] J. Y. Lee and D. S. Cho, "The eating behavior and food preference of preschool children in Sungnam day care facilities," Korean Journal of Food and Nutrition, vol. 19, no. 4, pp. 482-495, 2006.

[7] A. R. Lee, Y. L. Yu, H. J. Kim, K. A. Kim, and K. W. Kim, "Status of dietary life related knowledge, self-efficacy, food preference and dietary behavior of preschoolers in Kyunggi area," Korean Journal of Community Nutrition, vol. 21, no. 3, pp. 274-283, 2016.

[8] D. Elsweiler and M. Harvey, "Towards automatic meal plan recommendations for balanced nutrition," in Proceedings of the 9th ACM Conference on Recommender Systems, Vienna, Austria, September 2015.

[9] E. S. Park, Y. H. Yee, and J. S. Lee, "Recommended dietary allowances for young children and food guidelines for preschool children in Sweden," Korean Journal of Community Nutrition, vol. 9, no. 6, pp. 742-752, 2004.

[10] B. Dheeraj, G. Sheetal, and M. Debajyoti, "Matrix factorization model in collaborative filtering algorithms: a survey," Procedia Computer Science, vol. 49, pp. 136-146, 2015.

[11] T. Zhou, Z. Kuscsik, J.-G. Liu, M. Medo, J. R. Wakeling, and Y.-C. Zhang, "Solving the apparent diversity-accuracy dilemma of recommender systems," Proceedings of the National Academy of Sciences, vol. 107, no. 10, pp. 4511-4515, 2010.

[12] J. Freyne and S. Berkovsky, "Recommending food: reasoning on recipes and ingredients," in User Modeling, Adaptation, and Personalization (UMAP), pp. 381-386, 2010.

[13] A. M. Roza and H. M. Shizgal, "The Harris benedict equation reevaluated: resting energy requirements and the body cell mass," The American Journal of Clinical Nutrition, vol. 40, no. 1, pp. 168-182, 1984.

[14] C. Anderson, A. Survey of Food Recommenders, Cornell University, Ithaca, NY, USA, 2018.

[15] W. Tansey, E. W. Lowe, and J. G. Scott, "Diet2Vec: multi-scale analysis of massive dietary data," in Proceedings of the 13th Conference on Neural Information Processing Systems (NIPS), Barcelona, Spain, 2016.

[16] D. Elsweiler, C. Trattner, and M. Harvery, "Exploiting food choice biases for healthier Recipe recommendation," in
Proceedings of the 40th International ACM SIGIR Conference on Research and Development in Information Retrieval, Tokyo, Japan, August 2017.

[17] T. N. T. Tran, M. Atas, A. Felfernig, and M. Stettinger, "An overview of recommender systems in the healthy food domain," Journal of Intelligent Information Systems, vol. 50, no. 3, pp. 501-526, 2018.

[18] T. Thomas, S. Vassilios, D. Kosmas, G. Lazaros, and D. Petros, "A survey on AI nutrition recommender systems," in Proceedings of the 12th ACM International Conference on PErvasive Technologies Related to Assistive Environments-PETRA'19, pp. 5-7, Rhodes, Greece, June 2019.

[19] J. A. Harris and F. G. Benedict, "A biometric study of human basal metabolism," Proceedings of the National Academy of Sciences of the United States of America, vol. 4, no. 12, pp. 370-373, 1918.

[20] S. Yun, D. Lim, K. Oh, J. Moon, and J. Kim, "Development of the 2017 Korean national growth charts for children and adolescents," Public Health Weekly Report, vol. 11, no. 25, pp. 813-820, 2017.

[21] Korea Center for Disease \& Prevention, http://www.cdc.go.kr/ $\mathrm{CDC} /$ main.jsp.

[22] H. Jung, 2015 Dietary Reference Intakes for Koreans, Ministry of Health and Welfare, Seoul, South Korea, 2015. 


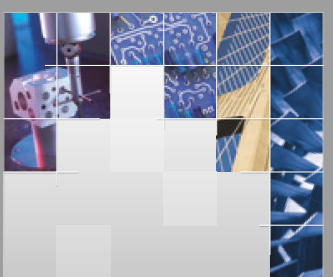

\section{Enfincering}
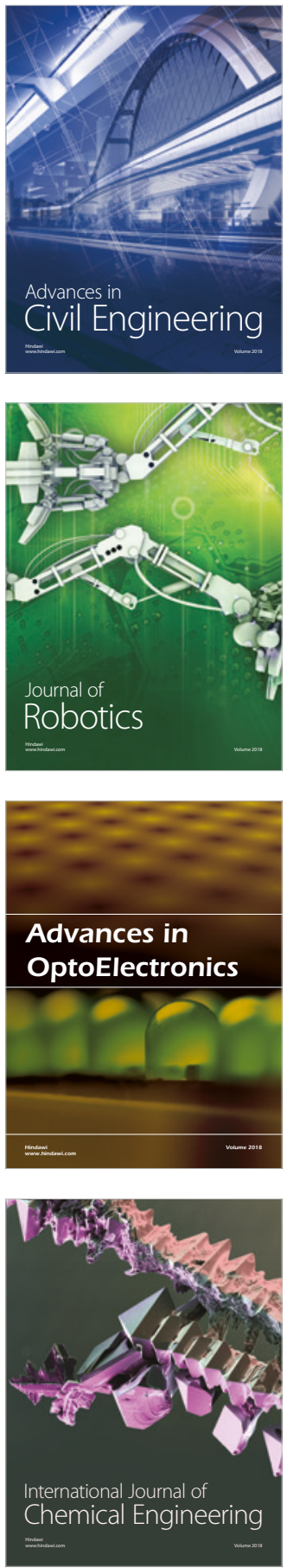

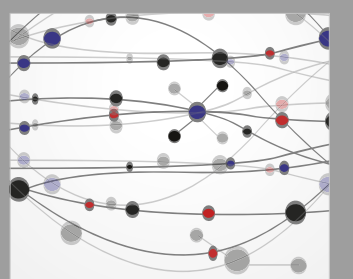

\section{Rotating \\ Machinery}

The Scientific World Journal

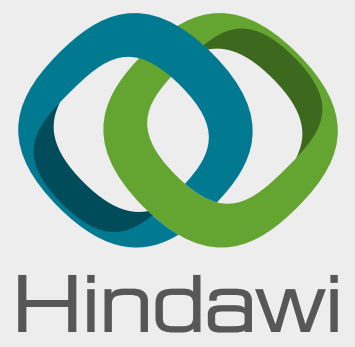

Submit your manuscripts at

www.hindawi.com
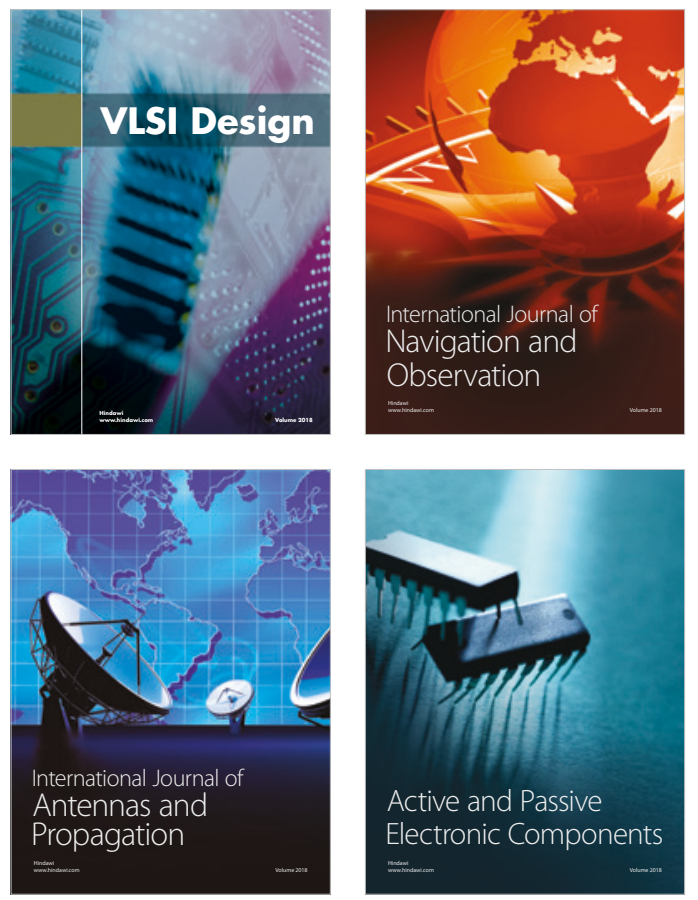
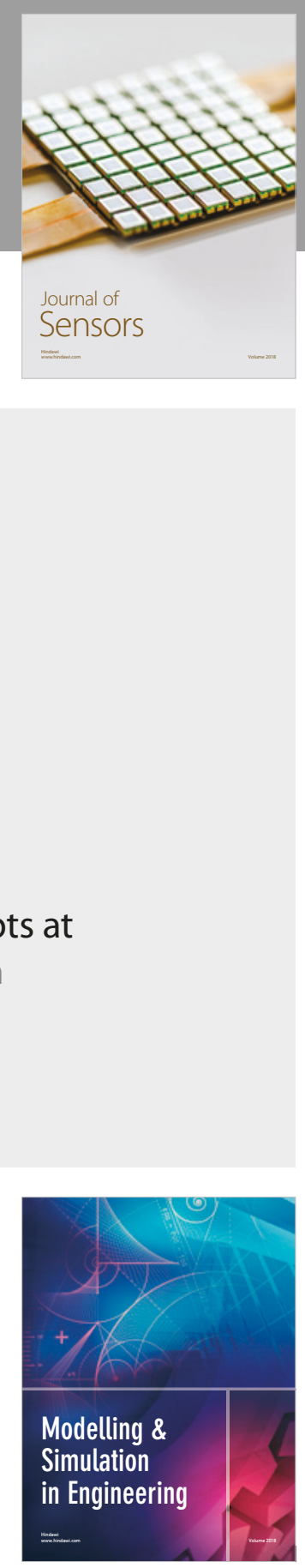

\section{Advances \\ Multimedia}
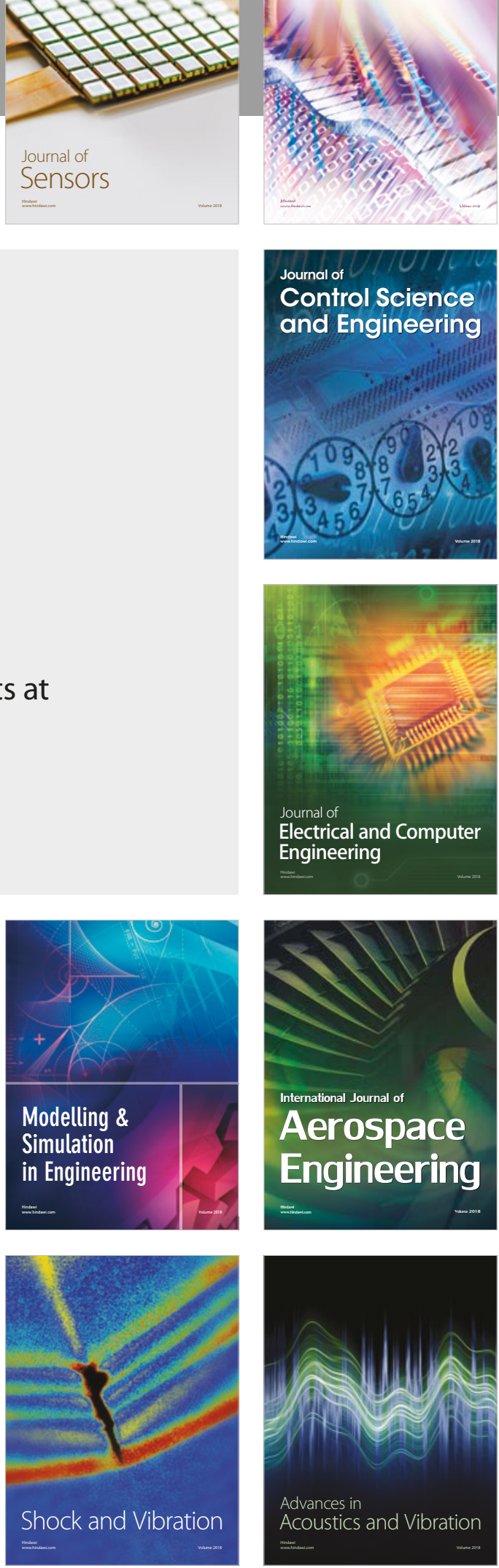